\title{
Reverse-transformation austenite structure control with micro/nanometer size
}

\author{
Hui-bin $W u^{1,2)}$, Gang Niu ${ }^{1,2)}$, Feng-juan $W u^{2)}$, and Di Tang ${ }^{1,2)}$ \\ 1) Collaborative Innovation Center of Steel Technology, University of Science and Technology Beijing, Beijing 100083, China \\ 2) Beijing Engineering Technology Research Center of Special Steel for Traffic and Energy, Beijing 100083, China \\ (Received: 1 September 2016; revised: 13 December 2016; accepted: 14 December 2016)
}

\begin{abstract}
To control the reverse-transformation austenite structure through manipulation of the micro/nanometer grain structure, the influences of cold deformation and annealing parameters on the microstructure evolution and mechanical properties of 316L austenitic stainless steel were investigated. The samples were first cold-rolled, and then samples deformed to different extents were annealed at different temperatures. The microstructure evolutions were analyzed by optical microscopy, scanning electron microscopy (SEM), magnetic measurements, and X-ray diffraction (XRD); the mechanical properties are also determined by tensile tests. The results showed that the fraction of stain-induced martensite was approximately $72 \%$ in the $90 \%$ cold-rolled steel. The micro/nanometric microstructure was obtained after reversion annealing at $820-870^{\circ} \mathrm{C}$ for $60 \mathrm{~s}$. Nearly $100 \%$ reversed austenite was obtained in samples annealed at $850^{\circ} \mathrm{C}$, where grains with a diameter $\leq 500 \mathrm{~nm}$ accounted for $30 \%$ and those with a diameter $>0.5 \mu \mathrm{m}$ accounted for $70 \%$. The micro/nanometer-grain steel exhibited not only a high strength level (approximately $959 \mathrm{MPa}$ ) but also a desirable elongation of approximately $45 \%$.
\end{abstract}

Keywords: austenitic stainless steel; structure control; martensite; reverse transformation; grain refinement

\section{Introduction}

Austenitic stainless steels have been widely used in artificial joints and other biomedical materials because of they are non-magnetic, corrosion-resistant, easy to shape, and exhibit good mechanical properties [1]. Their only drawback is that the biocompatibility of austenitic steel is obviously inferior to that calcium phosphate and bioactive glass. Misra et al. [2-5] have authored several recent reviews related to the biomedical applications of ultrafine-grained steel. They noted that nanocrystals with sizes of $500 \mathrm{~nm}$ or less tend to improve cell viability and promote the formation of bone lipoprotein. Micron-sized grains $(0.5-2 \mu \mathrm{m})$ can facilitate cell adhesion and stimulate metabolic activity, which imparts austenitic stainless steels with a micro/nanometer composite structure with better human histocompatibility compared to that of the traditional coarse-grained medical stainless steel.

Microstructure is one of the most important factors determining the mechanical properties of steel materials. Many microstructure control technologies have emerged in the course of development of the traditional structural steels to improve their mechanical performance [6-11]. Steel materials with excellent combinations of strength and toughness have been obtained through various microstructure refinement technologies. From the late 1990s to the beginning of this century, research on the ferrite refinement limit was carried out in Japan, South Korea, the European Union, and Australia, among other countries. In the same period, the theory of deformation-induced ferrite phase transition (DIFT) was proposed by researchers in China [12-13]. Their results demonstrated that the yield strength of carbon structural steel was improved from 200 to $400 \mathrm{MPa}$ when the ferrite grains were refined from 20 to $5 \mu \mathrm{m}$. The yield strength of the micro-alloyed steel was improved from 400 to $700 \mathrm{MPa}$ when the grain size was refined from more than $10 \mu \mathrm{m}$ to 2 $\mu \mathrm{m}$. The strength of the bainite/martensite multiphase microstructure was also significantly improved by refinement. It was based on the bainite transformation theory proposed by Bhadeshia's group [14] at the University of Cambridge, who designed a high-carbon steel with a bainite transformation temperature under $200^{\circ} \mathrm{C}$. The bainite laths size was re-

Corresponding author: Gang Niu E-mail: ustbning@163.com 
fined to the nanometer level, and the residual austenite with high toughness was retained in the microstructure, which resulted in a hardness of $600 \mathrm{HV}$ and a strength of $2500 \mathrm{MPa}$. However, many approaches to refining grains are not suitable for stainless steel. For instance, the thermomechanical control process (TMCP) generally results in a coarse grain size on the order of 20 to $40 \mu \mathrm{m}$ depending on the processing conditions.

We hypothesized that, if the microstructure of $316 \mathrm{~L}$ stainless steel could be processed into a micro/nanometer composite microstructure, it would not only exhibit good biocompatibility, but also a good combination of strength and plasticity. Therefore, in this work, we investigated how to achieve grains with a micro/nanocomposite structure in 316L steel using special microstructure control technology.

\section{Experimental procedure}

The chemical composition of the $316 \mathrm{~L}$ austenitic stainless steel was (in wt\%) C 0.025, Si 0.66, Mn 0.79, Cr 16.8, Ni 10.2, Mo 2.16, N 0.09, and balance Fe. The tested steel sheet was obtained by the hot rolling process. The samples were heated to $1050^{\circ} \mathrm{C}$ and maintained at this temperature for $12 \mathrm{~min}$ for solution treatment. The initial austenite grain size was in the range from 5 to $20 \mu \mathrm{m}$, as shown as in Fig. 1. Cold deformation with $40 \%, 60 \%, 80 \%$, and $90 \%$ total thickness reduction was carried out in this work. The annealing experiments were carried out on a CCT-AV-II annealing simulation machine for the samples with the different cold deformation reductions. The heating rate was $30^{\circ} \mathrm{C} / \mathrm{s}$ to a holding temperature ranging from 700 to $1000^{\circ} \mathrm{C}$; the soaking time was $60 \mathrm{~s}$ on continuous annealing.

The microstructural evolutions were analyzed using optical microscopy (Zeiss Axiovert 40MAT) and scanning electron microscopy (ZEISS ULTRA 55). A Feritescope (Quantum Design-PPMS) was used to measure the amount of ferromagnetic martensite phase. X-ray diffraction (XRD) measurements (Rigaku DMAX-RB with $\mathrm{Cu} \mathrm{K}_{\alpha}$ radiation) were used to identify the phases. All specimens were prepared by electropolishing at a voltage of $15 \mathrm{~V}$ for $25 \mathrm{~s}$, where the electrolyte was composed of $20 \mathrm{vol} \%$ perchloric acid and $80 \%$ ethanol [15]. Electron backscatter diffraction was used for microscopic characterization. In situ tensile tests were carried out on the in situ tensile experiment table of the JEM-2100 transmission electron microscope. The tensile tests were carried out at room temperature using a CMT5105 tensile machine. Vickers microhardness values were measured on a HV-1000 micro-Vickers durometer.

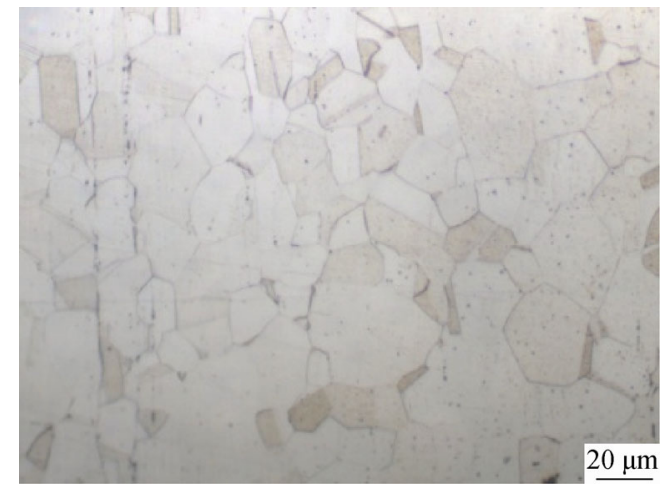

Fig. 1. Original grain structure of the as-received coarse-grained sheet.

\section{Results and discussion}

\subsection{Effect of cold deformation on strain-induced mar- tensite transformation}

The XRD results before and after cold deformation of 316L austenitic stainless steel are presented in Fig. 2. Only three diffraction peaks were observed for the samples without cold deformation; these peaks correspond to the (200), (220), and (311) crystal planes, respectively. That is, the microstructure of the solution-treated samples exhibited fully austenitic structures. Two new peaks attributable to body centered cubic (bcc) martensite appeared after cold deformation. The diffraction planes corresponding to these two peaks were the bcc (200) and (211) planes. The austenitic diffraction peak intensity gradually decreased and the martensite diffraction peak intensity gradually increased with increasing extent of cold deformation, as shown as in Fig. 2. The volume fraction of the strain-induced martensite in the $90 \%$ cold-rolled samples was approximately $72 \%$, as shown in Fig. 3.

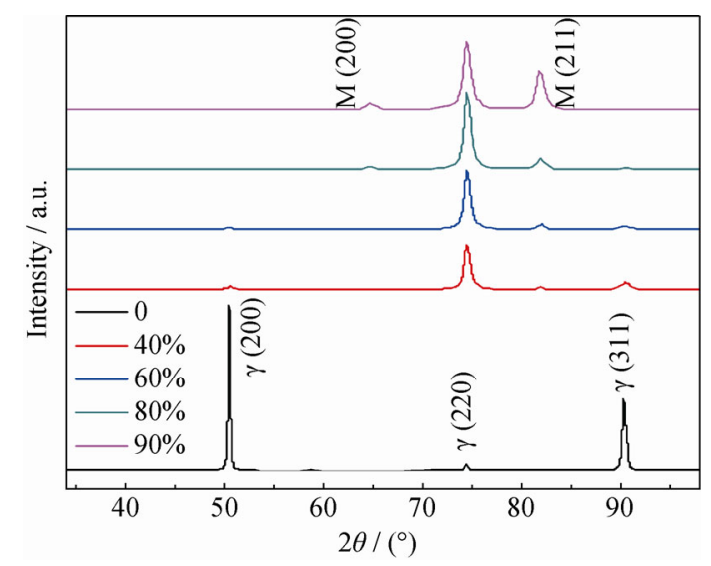

Fig. 2. X-ray diffraction patterns of the cold-rolled $316 \mathrm{~L}$ stainless steel. 


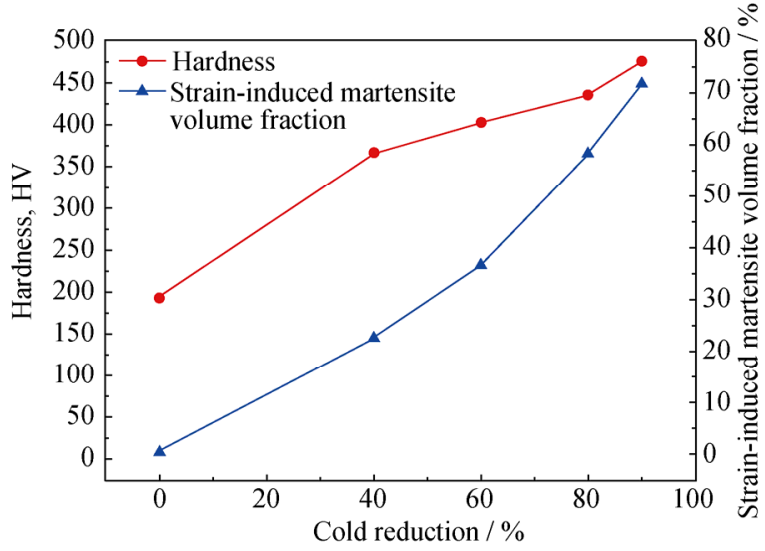

Fig. 3. Volume fraction of martensite and hardness of $316 \mathrm{~L}$ stainless steel subjected to different cold-rolling reductions.

The original sample was almost non-magnetic, and the austenite fraction was nearly $100 \%$, as shown in Fig. 4 . The saturation magnetization $\left(M_{\mathrm{s}}\right)$ gradually increased with increasing cold deformation, which indicates that the volume fraction of martensite increased with increasing cold deformation.

According to the peak positions shown in Fig. 2 as well as the samples' magnetic characteristics after cold deformation, we concluded that the austenitic phase transformation occurred in the $316 \mathrm{~L}$ stainless steel and that the new peaks

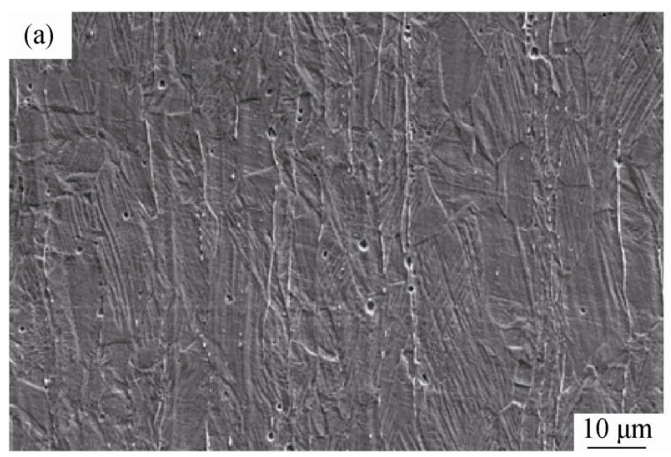

after cold deformation were the diffraction peaks of bcc-structured martensite. The strain-induced martensite fraction increased with increasing cold deformation. The twins, the grain deformation degree, and the crystal defects also increased with increasing cold deformation [16]. The elongated grains along the rolling direction exhibited flat or striped shapes. Greater cold deformation resulted in greater grain elongation. The grain boundaries became blurred, and the individual grains were indiscernible, exhibiting a fibrous structure when the cold deformation reached a certain extent, as shown as in Fig. 5.

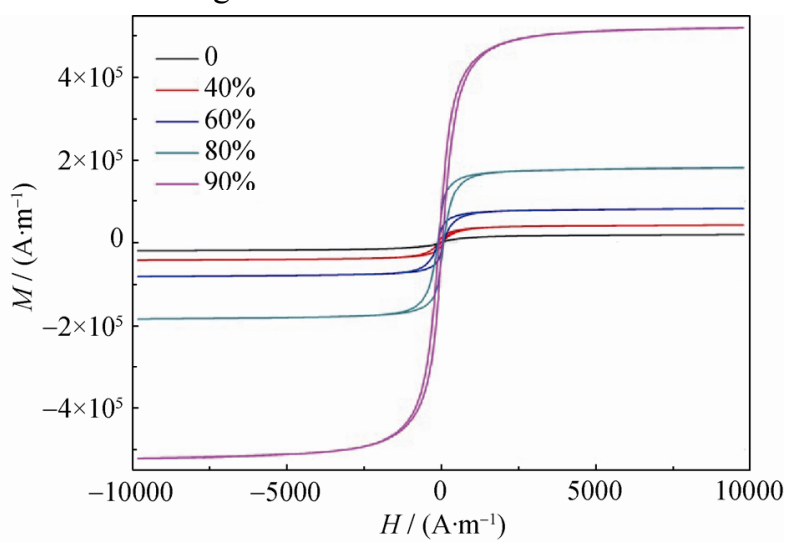

Fig. 4. Magnetic hysteresis loop of 316L stainless steel samples subjected to different cold-rolling reductions.

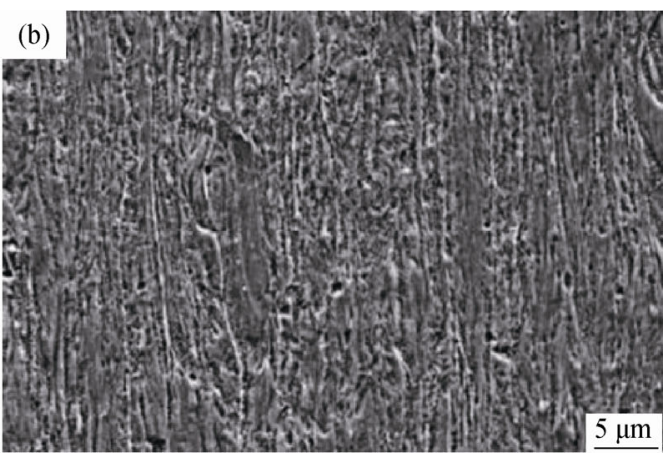

Fig. 5. SEM micrographs of the grain structure of $40 \%$ (a) and $90 \%$ (b) cold-rolled sheets.

\subsection{Reverse transformation of austenite after annealing}

The microstructures were determined by the reverse-transformation kinetics, which, in turn, was related to the cold deformation [17-18]. The metastable austenitic phase was transformed to the martensite after cold deformation, and the strain-induced martensite lath structure was destroyed preferentially via the large deformation to the refined structure during the cold rolling [16]. Many boundaries were present in the fine grain structure, which provided advantageous sites for recrystallization nucleation; thus, the grain structure favored grain refining of the reversed austenitic transformation by the large deformation [19]. The annealing experiments were carried out for samples subjected to $90 \%$ cold deformation. Fig. 6 shows the XRD results. The fraction of reversed austenite increased with the increasing annealing temperature. The austenite volume fraction was approximately $63 \%$ in the sample annealed at $750^{\circ} \mathrm{C}$ for $60 \mathrm{~s}$, but increased to $74 \%$ when the annealing temperature was increased to $800^{\circ} \mathrm{C}$ for $60 \mathrm{~s}$. The austenite percentage was approximately $94 \%$ in the sample annealed at $820^{\circ} \mathrm{C}$ for $60 \mathrm{~s}$, and the specimen annealed at $850^{\circ} \mathrm{C}$ for $60 \mathrm{~s}$ was completely reversed to austenite (nearly $100 \%$ ). 


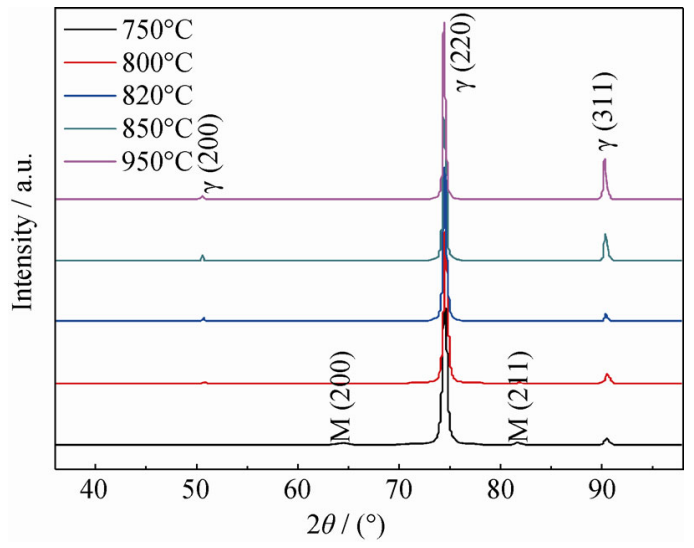

Fig. 6. X-ray diffraction patterns of $90 \%$ cold-rolled sheet specimens subjected to reversion annealing at different temperatures.

The microstructures of the samples with $90 \%$ cold deformation and annealed at different temperatures are shown in Fig. 7. The large deformation of the samples provided a high nucleation rate that resulted in more austenite grains in the subsequent annealing process. The distribution of austenite grain size in the sample annealed at the different temperatures is shown in Table 1 . The austenite fraction with a grain diameter $\leq 500 \mathrm{~nm}$ accounted for $38 \%$, and the austenite fraction with a grain diameter $>0.5 \mu \mathrm{m}$ accounted for $62 \%$ for the samples annealed at $800^{\circ} \mathrm{C}$ for $60 \mathrm{~s}$. The austenite fraction with the grain diameter $\leq 500 \mathrm{~nm}$ accounted for $35 \%$, and the austenite with the grain diameter $>0.5 \mu \mathrm{m}$ accounted for $65 \%$ for the samples annealed at $820^{\circ} \mathrm{C}$ for $60 \mathrm{~s}$.
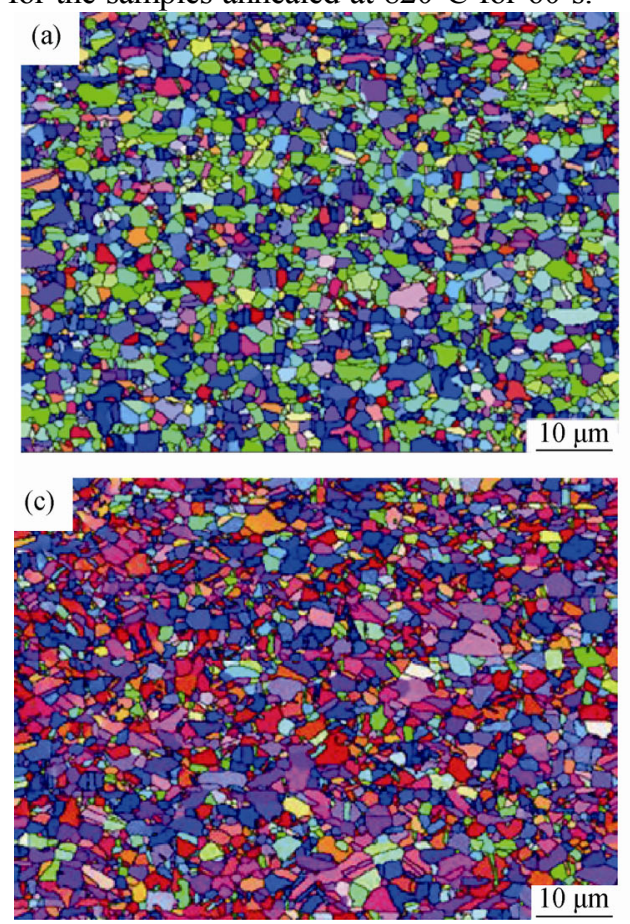

The microstructures were substantially refined compared to the original sample austenite grains, and Fig. 7 shows the reversed austenite with the micro/nanometer composite structure. The coarse austenite did not transform into martensite during the cold deformation process. The microstructure transformation was mainly related to the evolution of the new fine austenite during the annealing process, and the fine and equiaxed grains were transformed from the fragmentized martensite laths formed via the cold deformation process. That is, the formation of new fine austenite grains was a result of the reverse transformation. Although the grains with a diameter $\leq 500 \mathrm{~nm}$ accounted for $30 \%$ of the total grains, and the grains with a diameter $>0.5 \mu \mathrm{m}$ accounted for $70 \%$ of the total grains in the samples annealed at $850^{\circ} \mathrm{C}$ for $60 \mathrm{~s}$, grain growth was not obvious compared to the samples annealed at $820^{\circ} \mathrm{C}$. Furthermore, the strain-induced martensite was completely reversed to austenite (close to $100 \%$ ) when the samples were annealed at $850^{\circ} \mathrm{C}$. The grains larger than $0.5 \mu \mathrm{m}$ accounted for $73 \%$, and the

Table 1. Effect of annealing temperature on the grain size (60 s)

\begin{tabular}{cccc}
\hline Temperature $/{ }^{\circ} \mathrm{C}$ & $d \leq 0.5 \mu \mathrm{m}$ & $0.5 \mu \mathrm{m}<d \leq 1.0 \mu \mathrm{m}$ & $d>1.0 \mu \mathrm{m}$ \\
\hline 800 & $38 \%$ & $36 \%$ & $26 \%$ \\
820 & $35 \%$ & $5 \%$ & $30 \%$ \\
850 & $29 \%$ & $31 \%$ & $40 \%$ \\
870 & $27 \%$ & $31 \%$ & $42 \%$ \\
900 & $23 \%$ & $25 \%$ & $52 \%$ \\
950 & $17 \%$ & $16 \%$ & $67 \%$ \\
\hline
\end{tabular}
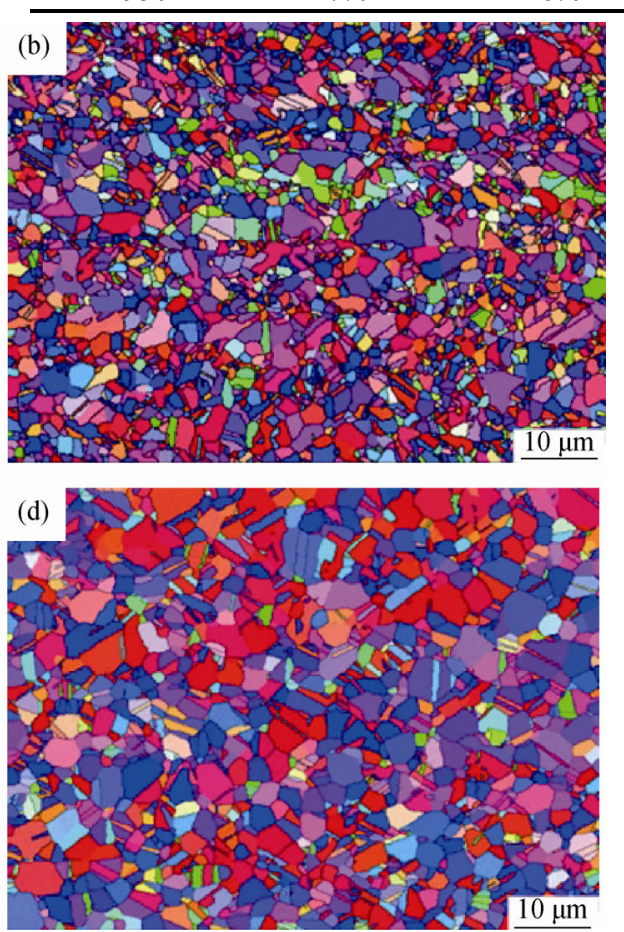

Fig. 7. Grain structures of the $90 \%$ cold-rolled sheet after reversion annealing at different temperatures for $60 \mathrm{~s}$ : (a) $820^{\circ} \mathrm{C}$; (b) $850^{\circ} \mathrm{C}$; (c) $870^{\circ} \mathrm{C}$; (d) $950^{\circ} \mathrm{C}$. 
grains with a diameter $\leq 500 \mathrm{~nm}$ accounted for $27 \%$ in the samples annealed at $870^{\circ} \mathrm{C}$ for $60 \mathrm{~s}$, as shown as in Fig. 7(c). In addition, the grains were not obviously coarsened compared to those of the samples annealed at $850^{\circ} \mathrm{C}$. When the annealing temperature was $900^{\circ} \mathrm{C}$, the grains began to grow and the grains with a diameter $\geq 500 \mu \mathrm{m}$ accounted for $78 \%$. We concluded that the microstructure with a small size grain was obtained by the shear reverse transformation in a very narrow temperature range [20]. The diffusion reverse transformation occurred with increasing temperature, which led to grain coarsening. The grains with a diameter $>0.5 \mu \mathrm{m}$ accounted for $83 \%$ in the samples annealed at $950^{\circ} \mathrm{C}$, and the grains obviously grew, as shown in Fig. 7(d). Therefore, when the strain-induced martensite is transformed into austenite, the annealing temperature should be as low as possible to control the grain growth [21]. On the basis of the aforementioned analysis, the micro/nanometer composite structure was obtained when the samples were annealed at $820-870^{\circ} \mathrm{C}$ for $60 \mathrm{~s}$, and the scheme with an annealing temperature of $850^{\circ} \mathrm{C}$ for $60 \mathrm{~s}$ was optimal.

\subsection{Mechanical properties}

The mechanical properties of the samples with $90 \%$ deformation and annealed at different temperatures are shown in Fig. 8. With increasing annealing temperature, the hardness decreased gradually. The changes in hardness were likely related to the defect density, the amount of strain-induced martensite, and the grain size of the reverse-transformation austenite. The hardness of the samples with $90 \%$ deformation was $476 \mathrm{HV}_{50}$. As shown in Fig. 8, the decrease of hardness was slow for samples annealed below $800^{\circ} \mathrm{C}$. However, when the annealing temperature exceeded $800^{\circ} \mathrm{C}$, the hardness decreased dramatically. The hardness decreased from $349 \mathrm{HV}_{50}$ for the sample annealed at $800^{\circ} \mathrm{C}$ to $256 \mathrm{HV}_{50}$ for the sample annealed at $820^{\circ} \mathrm{C}$. In addition, in the sample annealed in $820^{\circ} \mathrm{C}$, the strain-induced martensite had largely disappeared. When the annealing temperature was in the range from 820 to $870^{\circ} \mathrm{C}$, the changes in hardness were not obvious because the microstructure of the samples did not obviously change and almost fully recrystallized in this temperature range. Furthermore, grain growth was also not obvious. Subsequently, the hardness was further decreased with increasing annealing temperature because of the substantial growth of austenite grains and the decrease of the dislocation density.

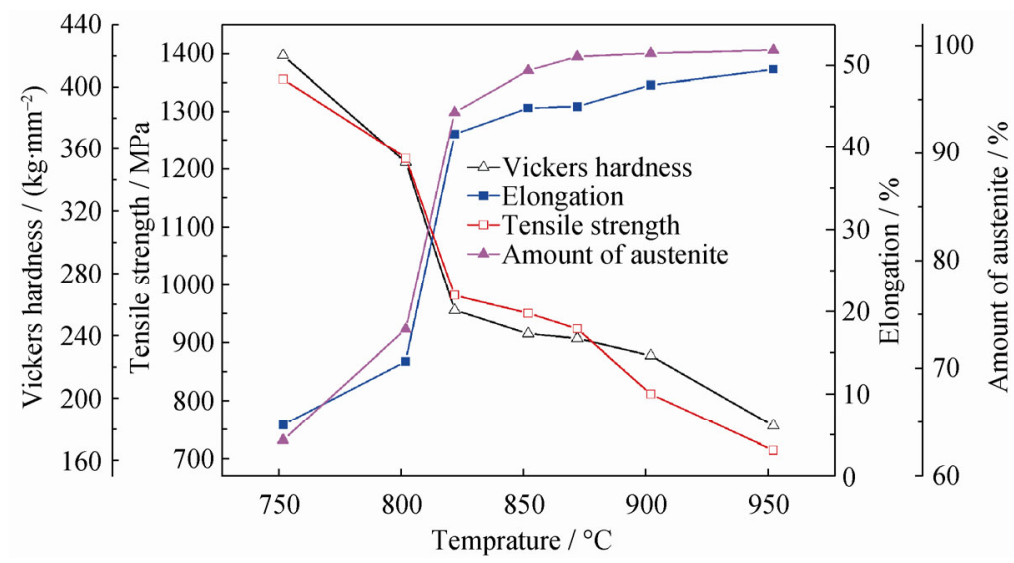

Fig. 8. Mechanical properties of the $90 \%$ cold-rolled sheet after reversion annealing at different temperatures.

As the annealing temperature increased, the tensile strength decreased; however, the elongation was gradually enhanced. The elongation was small when the samples were annealed at $750^{\circ} \mathrm{C}$ or $800^{\circ} \mathrm{C}$, where the effects of work hardening were still observed. The microstructure did not obviously change compared to that of the cold-deformed specimens. A large amount of twins, dislocations and martensite were still present, which made the mechanical properties change only slightly. The elongation increased sharply when the samples were annealed at $820^{\circ} \mathrm{C}$, and the mechanical properties were improved substantially. The product of strength and elongation increased from $16340 \mathrm{MPa} \%$ to $41001 \mathrm{MPa} \%$ when the annealing temperature was increased from $800^{\circ} \mathrm{C}$ to $820^{\circ} \mathrm{C}$ at an annealing time of $60 \mathrm{~s}$.
This increase is attributed to microstructure defects being further eliminated with increasing annealing temperature. Meanwhile, the recrystallized grain size of the specimen annealed at $820^{\circ} \mathrm{C}$ was very small, which contributes greatly to the strength. Therefore, the elongation increased while the samples retained a high tensile strength. The mechanical properties were further improved when the annealing temperature was increased to $850^{\circ} \mathrm{C}$, and the product of strength and elongation reached $42782 \mathrm{MPa} \%$. Furthermore, the strain-induced martensite had been completely reversed to austenite. The grain size changed little compared to that of the specimen annealed at $820^{\circ} \mathrm{C}$; therefore, strength and plasticity matched much better than those of the original $316 \mathrm{~L}$ austenitic stainless steel sample. The tensile strength reached 
$959 \mathrm{MPa}$, and the elongation was $45 \%$; by contrast, the tensile strength and elongation of the original specimen were only $664 \mathrm{MPa}$ and $58 \%$, respectively, and the austenite grain size of the original samples was in the range from 5 to $20 \mu \mathrm{m}$.

In the case of the sample subjected to $90 \%$ cold deformation and annealed at $850^{\circ} \mathrm{C}$ for $60 \mathrm{~s}$, the grains with a diameter $\leq 500 \mathrm{~nm}$ accounted for $30 \%$ and those $>1.0 \mu \mathrm{m}$ accounted for $39 \%$. Therefore, a composite structure of micro/nanometer grains was obtained. The grains were not obviously coarsened when the samples were annealed at $870^{\circ} \mathrm{C}$ for $60 \mathrm{~s}$, and the elongation increased while the tensile strength was not substantially diminished. However, secondary recrystallization occurred when the annealing temperature was increased further, as shown in Fig. 7(d); in addition, some grains with abnormal growth were found, and these grains led to dramatically decreased tensile strength. In the case of samples annealed at $950^{\circ} \mathrm{C}$ for $60 \mathrm{~s}$, the product of strength and elongation was reduced to $36422 \mathrm{MPa} \%$, which is even lower than that of the original sample (38203 MPa.\%). Compared with the microstructure of the original sample, the grains obviously grew. Meanwhile, the micro/nanocomposite structure of the grains gradually disappeared when the samples were annealed at $950^{\circ} \mathrm{C}$. A small amount of carbides precipitated along the grain boundaries, which led to the decrease of the mechanical properties.

\subsection{Coordinating role of micro/nanograins in the de- formation process}

To elucidate the mechanism of the coordinated deformation
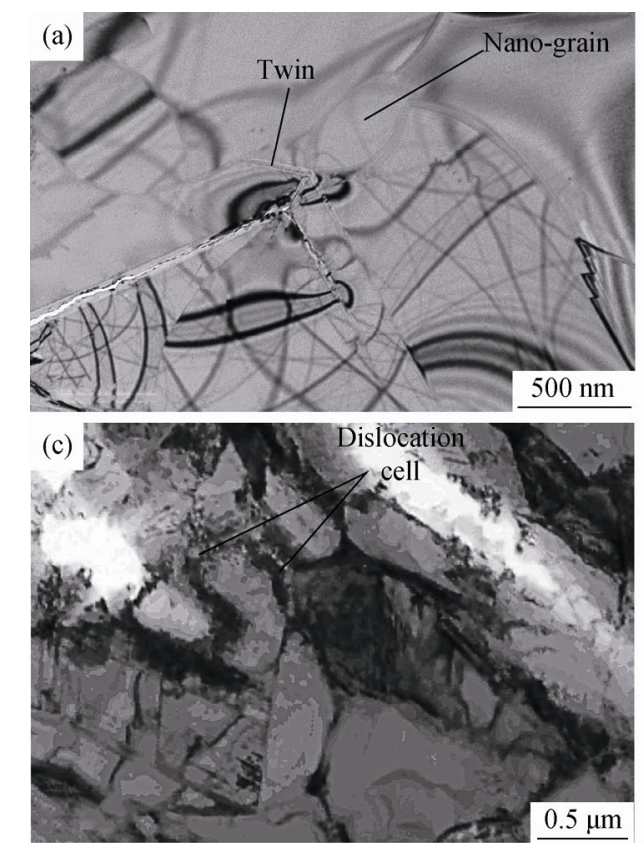

for micro/nanocomposite-structured grains, we carried out in situ tensile tests. The movements of dislocations in the micro/nanocomposite-structured grains during the deformation are shown in Fig. 9. The dislocations originated in the large grains (micrograins), and its movement was hindered by grain boundaries. In addition, smaller grain sizes resulted in a larger grain-boundary area. Therefore, the movement of dislocations in the fine grains became increasingly difficult. Of course, the slip band can also move transversely. In addition, with constant movement of the slip bands, dislocation pile-up occurred in the boundaries, as shown in Fig. 9(b). However, the slip bands continued to move when the dislocation pile-up reached a certain extent. The dislocation pile-up occurred in the nanograin boundaries, and the multi-directional movement of slip bands can avoid stress concentration. The further expansion of cracks in the smaller grains can be prevented through releasing the stress of the twin. The large grains easily deformed, whereas the small grains were relatively stable. The dislocations moved along the nanoscale grain boundaries and formed a dislocation cell because of the blocking of grain boundaries when the dislocations moved to smaller grains, as shown in Fig. 9(c). The large grains (micrograins) first deformed, which contributed to the plasticity. When the deformation of large grains reached a certain extent, the small grains (nanograins) began to deform, which contributed to the strength. Moreover, the large grains and small grains were well matched in the samples annealed at $850^{\circ} \mathrm{C}$ for $60 \mathrm{~s}$, where the product of strength and elongation reached its highest value among the investigated samples.

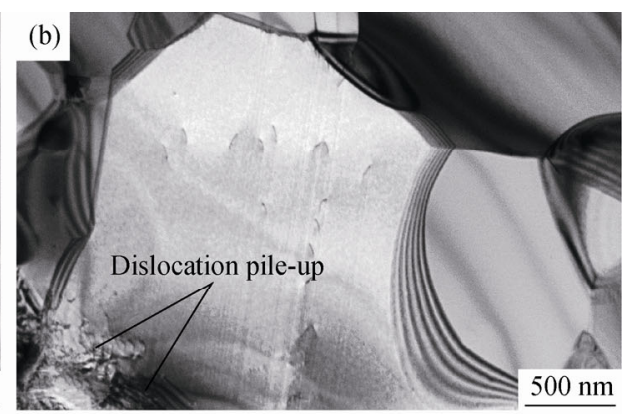

Fig. 9. Movements of dislocations in the micro/nanostructure: (a) micro/nanostructure; (b) dislocation pile-up; (c) dislocation cell. 


\section{Conclusions}

(1) The diffraction peak intensity of martensite and the $M_{\mathrm{s}}$ increased with increasing cold deformation of $316 \mathrm{~L}$ stainless steel. When the cold deformation was $90 \%$, the strain-induced martensite fraction was approximately $72 \%$. The grains were elongated along the direction of deformation. Large amounts of deformation twins, lath martensite, and high-density dislocations were present.

(2) After $90 \%$ cold rolling, the micro/nanocomposite structure was obtained when the samples were annealed in the range from 820 to $870^{\circ} \mathrm{C}$ for $60 \mathrm{~s}$. The fraction of austenite approached $100 \%$ when the samples were annealed at $850^{\circ} \mathrm{C}$ for $60 \mathrm{~s}$, whereas grains with a diameter $\leq 500 \mathrm{~nm}$ accounted for $30 \%$ and grains with a diameter $>0.5 \mu \mathrm{m}$ accounted for $70 \%$. The steel with the micro/nanocomposite structure not only exhibited a high strength level (approximately $959 \mathrm{MPa}$ ) but also exhibited a desirable elongation (approximately 45\%), which resulted in a better match of the strength and plasticity compared to the case of the original 316L stainless steel.

(3) The large grains (micrograins) were more easily deformed, which contributed to the plasticity. When the deformation of large grains reached a certain extent, the small grains (nanograins) started to deform. Therefore, the main contributor to the strength was the small grains.

\section{Acknowledgements}

This research was supported by the National Natural Science Foundation of China (Grant No. 51474031).

Open Access This article is distributed under the terms of the Creative Commons Attribution 4.0 International License (http://creativecommons.org/licenses/by/4.0/), which permits unrestricted use, distribution, and reproduction in any medium, provided you give appropriate credit to the original author(s) and the source, provide a link to the Creative Commons license, and indicate if changes were made.

\section{References}

[1] R.D.K. Misra, W.W. Thein-Han, T.C. Pesacreta, M.C. Somani, and L.P. Karjalainen, Biological significance of nanograined/ultrafine-grained structures: Interaction with fibroblasts, Acta Biomater., 6(2010), No. 8, p. 3339.

[2] R.D.K. Misra, W.W. Thein-Han, S.A. Mali, M.C. Somani, and L.P. Karjalainen, Cellular activity of bioactive nanograined/ultrafine-grained materials, Acta Biomater., 6(2010), No. 7, p. 2826.
[3] S. Mali, R.D.K. Misra, M.C. Somani, and L.P. Karjalainen, Biomimetic nanostructured coatings on nano-grained/ultrafine-grained substrate: microstructure, surface adhesion strength, and biosolubility, Mater. Sci. Eng. C, 29(2009), No. 8, p. 2417.

[4] P.K.C. Venkatsurya, W.W. Thein-Han, R.D.K. Misra, M.C. Somani, and L.P. Karjalainen, Advancing nanograined/ultrafine- grained structures for metal implant technology: interplay between grooving of nano/ultrafine grains and cellular response, Mater. Sci. Eng. C, 30(2010), No. 7, p. 1050.

[5] R.D.K. Misra, B.R. Kumar, M. Somani, and P. Karjalainen, Deformation processes during tensile straining of ultrafine/nanograined structures formed by reversion in metastable austenitic steels, Scripta Mater., 59(2008), No. 1, p. 79.

[6] B. Hwang and C.G. Lee, Influence of thermomechanical processing and heat treatments on tensile and Charpy impact properties of $\mathrm{B}$ and $\mathrm{Cu}$ bearing high-strength low-alloy steels, Mater. Sci. Eng. A, 527(2010), No. 16-17, p. 4341.

[7] X.W. Kong, L.Y. Lan, Z.Y. Hu, B. Li, and T.Z. Sui, Optimization of mechanical properties of high strength bainitic steel using thermo-mechanical control and accelerated cooling process, J. Mater. Process. Technol., 217(2015), p. 202.

[8] H.X. Yin, A.M. Zhao, Z.Z. Zhao, X. Li, S.J. Li, H.J. Hu, and W.G. Xia, Influence of original microstructure on the transformation behavior and mechanical properties of ultra-high-strength TRIP-aided steel, Int. J. Miner. Metall. Mater., 22(2015), No. 3, p. 262.

[9] T. Sakai, A. Belyakov, R. Kaibyshev, H. Miura, and J.J. Jonas, Dynamic and post-dynamic recrystallization under hot, cold and severe plastic deformation conditions, Prog. Mater Sci., 60(2014), p. 130.

[10] I.A. Yakubtsov, P. Poruks, and J.D. Boyd, Microstructure and mechanical properties of bainitic low carbon high strength plate steels, Mater. Sci. Eng. A, 480(2008), No. 1-2, p. 109.

[11] X.X. Xu, Y. Yu, W.L. Cui, B.Z. Bai, and J.L. Gu, Ultra-high cycle fatigue behavior of high strength steel with carbide-free bainite/martensite complex microstructure, Int. J. Miner. Metall. Mater., 16(2009), No. 3, p. 285.

[12] Y.Q. Weng, achievements of new generation steels program in china, Mater. Rev., 18(2004), p. 68.

[13] M.M. Tong, J. Ni, Y.T. Zhang, D.Z. Li, and Y.Y. Li, Temporal oscillatory behavior in deformation induced ferrite transformation in an Fe-C binary system, Scripta Mater., 50(2004), No. 6, p. 909.

[14] C. Garcia-Mateo, F.G. Caballero, and H.K.D.H. Bhadeshia, Development of hard bainite, ISIJ Int., 43(2003), No. 8, p. 1238.

[15] F. Forouzan, A. Najafizadeh, A. Kermanpur, A. Hedayati, and R. Surkialiabad, Production of nano/submicron grained AISI 304L stainless steel through the martensite reversion process, Mater. Sci. Eng. A, 527(2010), No. 27, p. 7334.

[16] R. Ueji, N. Tsuji, Y. Minamino, and Y. Koizumi, Ultragrain 
refinement of plain low carbon steel by cold-rolling and annealing of martensite, Acta Mater., 50(2002), No. 16, p. 4177.

[17] W. Jiang, D. Ye, J. Li, J. Su, and K.Y. Zhao, Reverse transformation mechanism of martensite to austenite in 00Cr15Ni7Mo2WCu2 super martensitic stainless steel, Steel Res. Int., 85(2014), No. 7, p. 1150.

[18] C. Ghosh, C. Aranas Jr., and J.J. Jonas, Dynamic transformation of deformed austenite at temperatures above the $\mathrm{Ae}_{3}$, Prog. Mater Sci., 82(2016), p. 151.

[19] K. Tomimura, S. Takaki, and Y. Tokunaga, Reversion mechanism from deformation induced martensite to austenite in metastable austenitic stainless steels, ISIJ Int., 31(1991), No. 12 , p. 1431.

[20] A. Belyakov, K. Tsuzaki, H. Miura, and T. Sakai, Effect of initial microstructures on grain refinement in a stainless steel by large strain deformation, Acta Mater., 51(2003), No. 3, p. 847.

[21] J. Han and Y.K. Lee, The effects of the heating rate on the reverse transformation mechanism and the phase stability of reverted austenite in medium Mn steels, Acta Mater., 67(2014), p. 354. 